\title{
Changes in Native Sentence Processing Related to Bilingualism: A Systematic Review and Meta-Analysis
}

\author{
Patricia Román ${ }^{1,2 *}$ and Irene Gómez-Gómez ${ }^{1}$ \\ 'Departamento de Psicología, Universidad Loyola Andalucía, Seville, Spain, ${ }^{2}$ Loyola Behavioral Lab, Universidad Loyola \\ Andalucía, Seville, Spain
}

\section{OPEN ACCESS}

Edited by:

Antonella Sorace,

University of Edinburgh,

United Kingdom

Reviewed by:

Ehab W. Hermena,

Zayed University, United Arab

Emirates

Patrick Sturt

University of Edinburgh,

United Kingdom

*Correspondence:

Patricia Román

proman@uloyola.es

Specialty section:

This article was submitted to

Language Sciences,

a section of the journal

Frontiers in Psychology

Received: 11 August 2021

Accepted: 27 January 2022

Published: 21 February 2022

Citation:

Román P and Gómez-Gómez (2022) Changes in Native Sentence Processing Related to Bilingualism:

A Systematic Review and Meta-Analysis.

Front. Psychol. 13:757023. doi: 10.3389/fpsyg.2022.757023
The native language changes as a result of contact with a second language, and the pattern and degree of such change depend on a variety of factors like the bilingual experience or the linguistic level. Here, we present a systematic review and meta-analysis of works that explore variations in native sentence comprehension and production by comparing monolinguals and bilinguals. Fourteen studies in the metaanalysis provided information regarding the bilingual experience and differences at the morphosyntactic level using behavioral methods. Overall, we observed that first language processing is subject to small transformations in bilinguals that occur in sentence comprehension and production. The magnitude of the changes depended on bilingual experiences, but only length of residence in an L2 setting predicted the degree of change, where shorter length of residence was associated with larger changes. Results are discussed and related to the cognitive processes that potentially cause the transformations in the first language. The present work reveals some limitations in the field that should be addressed in future studies to better understand the mechanisms behind language attrition.

\section{Keywords: bilingualism, sentence processing, L2 to L1 influence, linguistic variation and change, systematic review, meta-analysis}

\section{INTRODUCTION}

When learning a language, individuals often rely on their native language (L1) to facilitate the acquisition of the second one (L2), but learners also find that the characteristics of their L1 interfere when they are incongruent with those in the second language (Lardiere, 2009; Libben and Titone, 2009; Macizo et al., 2010; Paolieri et al., 2010; Casaponsa et al., 2015; Peristeri et al., 2018; Contemori et al., 2019, among others). Therefore, an extensive line of work in bilingualism has been devoted to exploring $\mathrm{L} 1$ influences on the L2.

Despite this interest, there is also evidence that contact with a second language transforms the processing of the L1 at different linguistic levels and carries a deviation from monolinguals (the so-called attrition, Schmid, 2010). For example, bilinguals are slower than monolinguals when they name pictures in their native language (e.g., Gollan et al., 2005), and they present more tip-of-thetongue states than monolinguals (Stasenko and Gollan, 2019) what suggests that they have reduced access to words in their L1. In addition, there are conceptual shifts where bilinguals change how they 
connect words to meanings (Pavlenko, 2000, 2004; Ameel et al., 2009; Pavlenko and Malt, 2011). At the grammatical level, research has found that learning a second language may yield modifications too, including gender assignments (e.g., Kaushanskaya and Smith, 2016) and parsing preferences such as changes in the likelihood with which bilinguals attach a relative clause to a specific noun in ambiguous sentences (Dussias, 2003, 2004; Dussias and Sagarra, 2007). Finally, there are also differences in brain activity, even when behavioral performance is similar between monolinguals and bilinguals (e.g., Bice and Kroll, 2015; Román et al., 2015).

Several causes have been proposed to explain the differences between monolinguals and bilinguals in their native language. Some authors state that the reduction in accessibility to the L1 representations in bilinguals may be related to a lesser frequency of L1 use (e.g., weaker links hypothesis; Gollan et al., 2008). In fact, variables associated with a reduction in the $\mathrm{L} 1$ input such as $\mathrm{L} 2$ proficiency and immersion in a context where the $\mathrm{L} 2$ is spoken (Gollan et al., 2008; Monaghan et al., 2017) seem to moderate the changes observed in bilinguals across time in, for example, fluency and naming tasks (Linck et al., 2009; Baus et al., 2013).

Another explanation for the phenomenon is the transfer of L2 features (Costa and Sebastián-Gallés, 2015). Investigations show bidirectional transfer (L1 to L2 and L2 to L1) not only at the lexical but also at the grammar level, which, according to the data, seems to be less permeable to influences from the L2 (Andersen, 1982; Hicks and Domínguez, 2020). One example comes from bilinguals speaking a language that allows omission of pronouns and a language where pronouns are always present. In a study by Sorace (2000), Italian-English bilinguals increased their production of overt pronouns in Italian (a null-pronoun language), and they did so in locations that were more usual in their second language (English, an overt-pronoun language) than in their native one (for example, before the verb rather than post-verbal subject pronouns in Italian-English bilinguals).

Finally, research has extensively demonstrated that, in bilinguals, both languages are co-activated even in contexts where only one is necessary (e.g., Hatzidaki et al., 2011; Bobb et al., 2020). This co-activation involves the recruitment of capacitylimited cognitive resources and mechanisms of control aimed to avoid interference from the non-intended language that may result in differences in how bilinguals process their L1 (e.g., Titone et al., 2011; Misra et al., 2012). Several circumstances can increase a load of resources, for instance, the unbalance between languages proficiency (e.g., the unintended language being more dominant), the complexity of sentence structure, or the similarity across languages. In this regard, increased coactivation can cause facilitation (e.g., cognates, words that are similar in form and meaning) or interference (e.g., homographs, words that are similar in form differ in meaning). Also, individual differences in cognitive control and working memory (Cunnings, 2017a,b) might influence the magnitude of L1 variation ${ }^{1}$.

Regardless of the processes implicated in how the L2 influences the native language in bilinguals, L1 attrition is not

\footnotetext{
${ }^{1}$ Here the term L1 variation refers to deviations from the normative use of the L1 in monolinguals.
}

a one-way road. Although, as mentioned above, the extent of L2 contact appears to be crucial in the occurrence and depth of changes in the L1, the L2 effects on the native language do not always seem constrained to high L2 proficiency, immersion, long-term exposure, or increased frequency of L2 use. Some studies reveal changes that emerge in adult learners after limited exposure to a new language in phonetic properties (Chang, 2012), lexicon (Baus et al., 2013; Bice and Kroll, 2015), and morphosyntax (Dussias et al., 2016), and with different timecourses and degrees of affection (Sorace, 2011). Again, the rapid variations observed in the L1 suggest that the native language is not a static entity, and in fact, such shifting is not necessarily linear or incremental. For example, Chang (2012) observed that native English speakers who were novice Korean learners presented after a few weeks of exposure to the L2 a phonological drift in their L1, that is, modifications that reflect the assimilation to phonetic characteristics of a different language. The author compared this group to experienced learners enrolled in the same course (Chang, 2013), and this latter group showed a reduced drift compared to their novice peers. Besides, reimmersion in the L1 environment may reverse the changes observed (Chamorro et al., 2015; Sorace, 2020), while, in other cases, the effects of the L2 contact may persist after individuals are no longer using it, and the duration of this influence diverges depending on the linguistic property under scrutiny (Linck et al., 2009).

The production and comprehension of sentences provide a rich and informative ground to explore the influence from L2 to L1. In a sentence, lexical, morphosyntactic, and pragmatic information interact, and individuals build upon these elements to convey or understand a message. Importantly, languages differ in terms of the weight that each of the aspects mentioned above has in a sentence and the information they provide, for example, case marking in German articles reveals the role of the subsequent noun in a sentence and is absent in Spanish or English. Concerning the influence of the L2 on L1 within sentence processing, linguistic levels differ in their degree of attrition after L2 acquisition, to give an example, bilinguals and monolinguals show similar responses to gender agreement violations in their native language but not to violations in verb combinations (Bergmann et al., 2015). Moreover, sentence production is more susceptible to cross-linguistic influences than comprehension (Runnqvist et al., 2013).

Although processes behind sentence production and comprehension partly coincide (e.g., Walenski et al., 2019), language production requires retrieval from memory, selection of intended representations, and speech planning processes subject to demands that may differ from reading or listening to sentences (Daneman and Green, 1986). Sentence production provides additional information too. Authors such as Schmid et al. (2013) consider that tasks where participants freely produce a discourse (for example, by asking them to report what they saw in an image or video fragment) allow bilinguals to display their entire repertoire without restrictions. All the above makes the study of sentences more informative than single-word studies about the circumstances that bilinguals face daily but more challenging to tackle. 
Studied variables that modulate the size of L1 variation in sentence processing could be divided into those related to the bilingual experience per se, linguistic variables, and individual differences in cognition. Within the first category, language dominance (Sanoudaki and Thierry, 2015; Kasparian et al., 2017), proficiency (Opitz, 2010; Cherciov, 2011), and frequency of use (Schmid and Dusseldorp, 2010; Kasparian and Steinhauer, 2017) have been more extensively explored. The results have led researchers to considering explanations in terms of weakened representations in L1 because of a reduced input and greater co-activation and competition between linguistic representations (Steinhauer and Kasparian, 2020). In this sense, immersion in the L2 environment represents an extreme case of exposure to L2 and limited contact with L1. For example, Dussias and Sagarra (2007) compared Spanish monolinguals, Spanish-English bilinguals with limited immersion in their L2 context, and Spanish-English bilinguals with extensive immersion while reading sentences that included a relative clause and two antecedent nouns (as in "An armed robber shot the sister of the actor who was in the balcony"). In such cases, Spanish speakers have a preference to attach the relative clause ("who was in the balcony") to the first noun ("the sister"), while native speakers of English prefer the second noun attachment ("the actor"). In their study, only bilinguals with long-term immersion in their L2 environment revealed an attachment in their L1 to the second noun, similar to native speakers of English.

Age of L2 acquisition (AoA) is another variable that has been associated with the degree of change in L1. AoA has been a matter of long debate in bilingual research under the assumption that while late bilinguals can master a second language, they hardly process morphosyntactical features the way monolinguals do (Wartenburger et al., 2003; Clahsen and Felser, 2006, but see Diependaele et al., 2011; Román et al., 2021). When considering its role in L2 to L1 influence, the question is whether some properties of the L1 become resistant to changes in late learners of L2 (Schmid and Köpke, 2017). Putting aside the case of heritage speakers (unbalanced bilinguals that learned their heritage language at home in a context where there is a dominant community language; see Benmamoun et al., 2013) that may not have fully consolidated their native language before they learn the second language, investigations addressing this matter are scarce (Karayayla and Schmid, 2019). Using semistructured interviews, Karayayla and Schmid (2019) collected free speech samples from highly proficient Turkish-English bilinguals with an AoA that range from 7 to $34 \mathrm{y}$-o and compared the occurrence of complex syntactical forms to a group of Turkish monolinguals. They did not find a relation between the AoA and the structural complexity.

Another aspect of interest within the bilingual experience is the degree of overlap between languages. As mentioned above, the extent to which languages share properties can determine the co-activation of languages, facilitating (e.g., Domínguez, 2013) or interfering with the integration of both linguistic systems (Steinhauer and Kasparian, 2020). For example, Bernolet et al. (2007) investigated whether bilinguals were more likely to repeat a syntactical structure in a language (a passive) after they had been exposed to that same structure in another language (cross-linguistic priming) when a confederate described a picture. They had participants that spoke languages with different (English-Dutch) or similar word order (Dutch-German). While they observed priming in constructions where the word order matched, they did not when it differed. Nevertheless, research shows changes in bilinguals who speak languages with different parsing preferences (noun attachment in relative clauses; Dussias, 2003, 2004; Dussias and Sagarra, 2007).

Regarding individual differences in cognition, accounts based on limited capacities due to co-activation or susceptibility to interference (Cunnings, 2017a) predict that higher cognitive control and working memory will reduce processing difficulties in bilingual sentence parsing (but see Brothers et al., 2021). Following the same rationale, cues that facilitate successful retrieval of information will help to overcome interference and bias sentence processing, as observed in studies investigating relative clause attachment (Dussias and Sagarra, 2007) or interpretation of null/overt pronouns (Tsimpli et al., 2004) and, therefore, they might be preferred and used by bilinguals (Cunnings, 2017a,b).

So far, mixed and limited results blur the connection between the mechanisms proposed to cause attrition and the outcomes in the studies, in part due to the heterogeneity of the bilingual experience. Here, we try to put together research on sentence processing to shed some light and pave the path to future inquiries.

\section{The Present Study}

Research demonstrates that the linguistic system is not a static unit but rather a malleable and adaptive organization that integrates novel entries at different levels (de Bot et al., 2007; Kroll et al., 2014; Kaan et al., 2019) and the context of sentence processing provides a broad but complex ground to investigate how various linguistic representations interact in the bilingual mind. In the present study, we present a systematic review and meta-analysis study to explore the current evidence on how the bilingual experience changes the processing of sentences in the native language to unravel different patterns and the factors that underlie them.

\section{METHODS}

We performed a systematic review and meta-analysis following the Preferred Reporting Items for Systematic Reviews and MetaAnalysis (PRISMA) guidelines (Moher et al., 2009). The protocol of this study was previously registered at PROSPERO on May $16^{\text {th }}, 2021$ (registration number CRD42021245042).

\section{Search Strategies}

The search was conducted in Web of Science (WOS), PsycINFO, PubMed, and Scopus from database inception to March 3, 2021, and the strategy comprised keywords and text words related to bilingualism, attrition, and sentence processing and comprehension. We first piloted the search strategy in WOS and then adapted it to run across PsycINFO, PubMed, and Scopus (see Supplementary Material). We also screened reference lists 


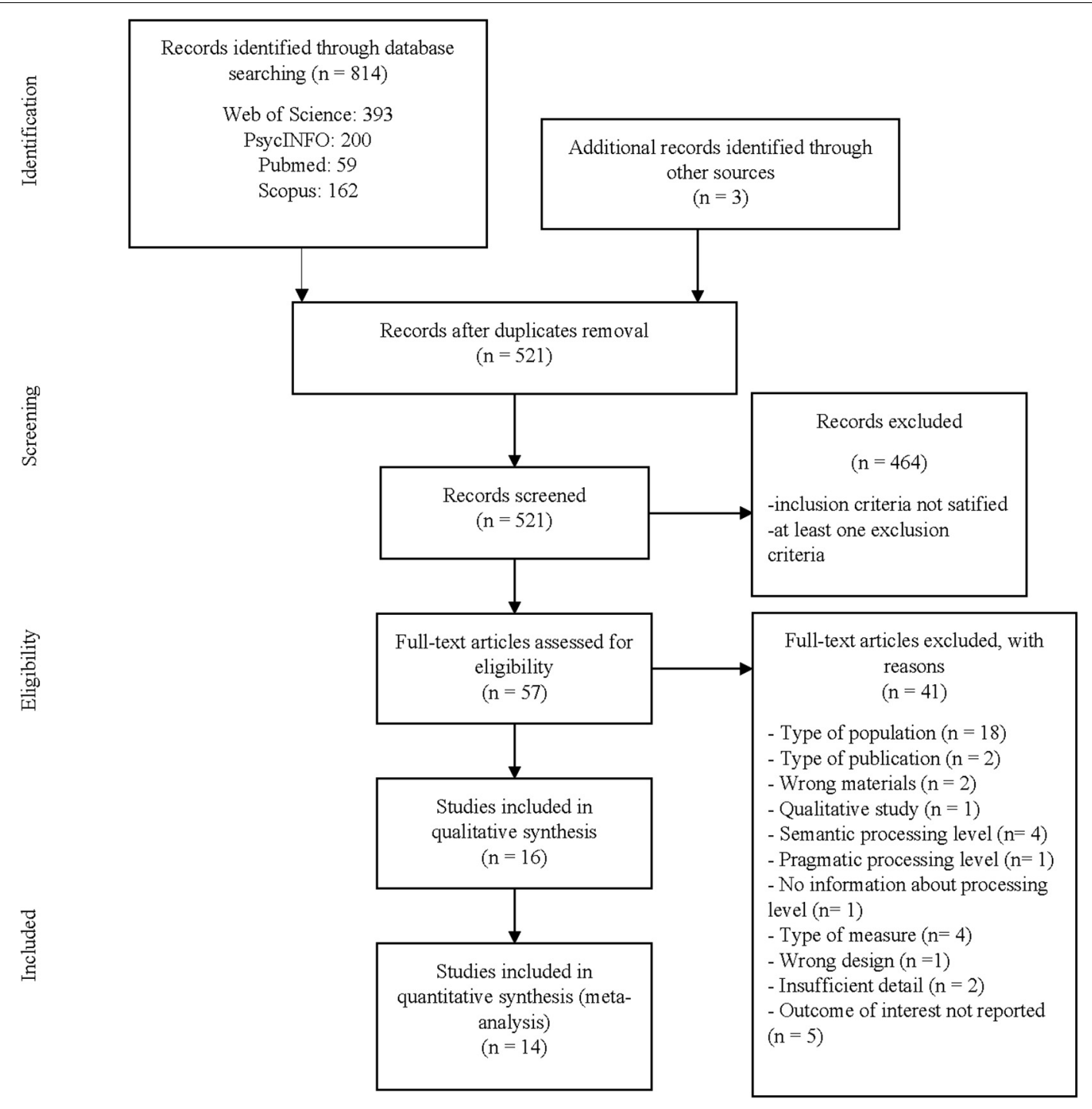

FIGURE 1 | PRISMA flow diagram of the studies.

of included studies and previous reviews on the topic. There were no language or year restrictions.

\section{Eligibility Criteria}

Following PICO criteria (population, intervention, comparator, and outcome), our inclusion criteria were as follows: the population was bilinguals, here broadly defined as participants tested in their native tongue but proficient in a second language; individuals suffering from any linguistic deficit, children, and heritage speakers were excluded; regarding intervention or exposures, we included cross-linguistic influence from the second language (L2) to the first language (L1) in morphosyntactic processing, and the comparator was morphosyntactic native language processing in bilingual participants contrasted to monolinguals' (participants with minimal to no experience with a language different from their native tongue) in both sentence comprehension and sentence production assessed by behavioral measures. Finally, the outcome of this study was the influence of the L 2 on the L1, as seen through different psycholinguistic tasks and behavioral measures.

\section{Selection of Studies}

Two independent reviewers screened the title and abstract (LG and IGG) and full text to assess the eligibility of the studies. A third reviewer made the final decision (PR) in case of disagreements. The software system used for recording decisions was Rayyan (Ouzzani et al., 2015).

\section{Data Extraction}

Again, two independent reviewers (PR and IGG) extracted the data and resolved discrepancies by consensus. We collected information related to the first author, publication year, total sample size, bilingual sample size, monolingual sample size, target population (pair of languages and language experience), 
cognitive processes studied (comprehension and production), task, and measures. More specifically, behavioral measures such as reaction times, accuracy, acceptability ratings in comprehension and pauses, errors, diversity, and complexity in production were included. Seven articles were discarded because of unavailable data, and information from groups of heritage speakers or children was not included in the analyses.

\section{Statistical Analysis}

Quantitative data were analyzed using the Comprehensive MetaAnalysis (CMA) software package, V.3 (CMA) (Borenstein et al., 2013) and Stata release 14.2. (StataCorp, 2015). First, standardized mean differences (SMDs) were calculated from each group's mean and SD, and when unavailable, we calculated SMDs from sample size and $p$-value. Then, CMA was used to obtain the equivalent SMDs. Finally, the pooled SMDs for all studies and their 95\% CIs were estimated. Some studies only reported $p$-values corresponding to interactions or group effects that included heritage speakers groups and were discarded from the analyses.

The SMD between bilingual and monolingual participants was used as effect size using Hedges' $g$ formula (Hedges, 1981) for small sample sizes. A negative value indicated higher scores in morphosyntactic tasks for the monolingual group in sentence comprehension and sentence production. Following previous evidence, the sign of the SMD was inverted for reaction time, errors, and pause measures so that the SMD went in the same direction as other measures such as accuracy in which the higher the mean, the better the performance (e.g., Beaussart et al., 2018). Interpretation of the resulting SMD followed Cohen's proposal: 0.20 as a small effect size, 0.50 as a medium effect size and, 0.80 as a large effect size (Cohen, 1988). In addition, random-effects models were used for pooling effect sizes assuming studies included heterogeneous populations that may differ from each other.

Inspection of heterogeneity was carried out through visual inspection of the forest plot, Q Cochran's statistic, and $p$-value. Additionally, heterogeneity was quantified by the $I^{2}$ index and its 95\% CI, and interpretation of the $I^{2}$ index was subject to the following level and percentages: unimportant heterogeneity $(0-40 \%)$, moderate heterogeneity (30-60\%), substantial heterogeneity (50-90\%), and considerable heterogeneity (75-100\%) (Higgins and Green, 2011; Borenstein et al., 2017).

We employed the Duval and Tweedie trim-and-fill procedure (Duval and Tweedie, 2000), the Begg and Mazumdar rank correlation (Begg and Mazumdar, 1994), and the Egger test (Stuck et al., 1998) to explore publication bias.

Furthermore, sensitivity analyses were conducted to explore SMD when Cohen's $d$ and the fixed-effects model were used. Finally, possible SMD variations were examined independently for studies focused on sentence comprehension, sentence production and for those exploring syntactic and morphological processing.

Finally, subgroup analyses were performed using a mixedeffects model for the categorical moderators AoA (early or late bilinguals), immersion context (either L1 or L2), length of residence (LoR) (short, long or no immersion), task modality (visual, auditorily and audiovisual), and structure congruence (similar and dissimilar across languages).

There was more than one effect size for all studies, and, therefore, the data might be considered dependent. Because of such dependence, we performed a meta-regression analysis on the continuous data with robust variance estimates (RVE; Hedges et al., 2010; Tanner-Smith and Tipton, 2014) using the Robumeta command in Stata. When fewer than four degrees of freedom were present, the results were considered unreliable (TannerSmith et al., 2016). Following previous research, covariates included in the RVE meta-regression were LoR, AoA, and L2 proficiency (e.g., Schmid and Dusseldorp, 2010). We performed both bivariate meta-regression analysis (including only one of the three independent variables in each meta-regression analysis) and multivariate meta-regression analysis (including all covariates in the same meta-regression analysis).

\section{RESULTS}

\section{Study Selection}

A total of 817 articles were identified through searching databases and other sources. After eliminating duplicates, 521 published studies and unpublished doctoral dissertations remained, and we screened the title and abstract. Fifty-seven studies initially met the inclusion criteria and were subject to a full-text inspection. This procedure yielded 16 articles that were included in the systematic review (see Figure $\mathbf{1}$ for details about the exclusion criteria). We finally included 14 studies with 14 independent group comparisons and 81 effect sizes for the meta-analysis calculations. Two studies (Castro et al., 2017; Dragoy et al., 2019) were excluded from the meta-analysis because they did not provide the needed statistics to calculate SMD.

\section{Study Characteristics}

A total of 1,044 participants were included across 16 studies in the systematic review (see Table 1 for study characteristics). Of them, 486 were bilinguals, and 412 were monolinguals. Ten studies included late bilinguals (studies IDs: 2, 5, 8, 9, $10,11,12,14,15$, and 16), three studies included only early bilinguals (studies 3, 7, and 13), another two studies included both late, and early bilinguals (studies 1 and 6) and one study did not provide information regarding the age of acquisition (study 4). Regarding the pair of languages under scrutiny, two studies investigated Spanish-Swedish bilinguals (studies 2 and 3). The following pairs were investigated in one study each: Turkish-German (study 1), English-Spanish (study 12), Spanish-English (study 10), Italian-English (study 16), GermanEnglish (study 14), Brazilian Portuguese-European Portuguese (study 4), Chinese-Korean (study 5), Russian-German (study 6), Turkish-English (study 7), Greek-Swedish (study 8), RussianHebrew (study 9), German-Dutch (study 11), German-Italian (study 15), German-Spanish (study 15), Greek-English (study 16), and Spanish-Catalan (study 13). Ten studies measured sentence comprehension (studies 1,2, 3, 4, 6, 7, 8, 9, 10, and 11) while five studies explored sentence production (studies 5 , 


\section{Target population}

\begin{tabular}{|c|c|c|c|c|c|c|c|c|c|}
\hline $\begin{array}{l}\text { Study } \\
\text { ID }\end{array}$ & References & $\begin{array}{l}\text { Total sample } \\
\text { size }\end{array}$ & $\begin{array}{l}\text { Bilingual } \\
\text { sample size }\end{array}$ & $\begin{array}{l}\text { Monolingual } \\
\text { sample size }\end{array}$ & Language experience & Pair of languages & Cognitive process & Task & Measures \\
\hline 1 & $\begin{array}{l}\text { Arslan et al., } \\
2015\end{array}$ & 61 & LB: 20; EB: 19 & 22 & $\begin{array}{l}\text { Early and late Turkish-German } \\
\text { bilinguals and Turkish monolinguals }\end{array}$ & Turkish-German & $\begin{array}{l}\text { Sentence } \\
\text { comprehension }\end{array}$ & Grammatical evidentiality & $\begin{array}{l}\text { Behavioral (ACC } \\
\text { and RT) }\end{array}$ \\
\hline 2 & $\begin{array}{l}\text { Bylund and } \\
\text { Ramírez-Galan, } \\
2014\end{array}$ & 59 & 39 & 20 & $\begin{array}{l}\text { Late Spanish-Swedish bilinguals and } \\
\text { Spanish monolinguals }\end{array}$ & Spanish-Swedish & $\begin{array}{l}\text { Sentence } \\
\text { comprehension }\end{array}$ & $\begin{array}{l}\text { Grammaticality Judgment } \\
\text { test }\end{array}$ & Behavioral (AR) \\
\hline 3 & $\begin{array}{l}\text { Bylund et al., } \\
2010\end{array}$ & 40 & 25 & 15 & $\begin{array}{l}\text { Early Spanish-Swedish bilinguals and } \\
\text { Spanish monolinguals }\end{array}$ & Spanish-Swedish & $\begin{array}{l}\text { Sentence } \\
\text { comprehension }\end{array}$ & $\begin{array}{l}\text { Grammaticality Judgment } \\
\text { test }\end{array}$ & Behavioral (AR) \\
\hline 4 & $\begin{array}{l}\text { Castro et al., } \\
2017\end{array}$ & 98 & 32 & 34 & $\begin{array}{l}\text { Brazilian Portuguese-European } \\
\text { Portuguese bilinguals, Brazilian } \\
\text { Portuguese monolinguals }\end{array}$ & $\begin{array}{l}\text { Brazilian } \\
\text { Portuguese-European } \\
\text { Portuguese }\end{array}$ & $\begin{array}{l}\text { Sentence } \\
\text { comprehension }\end{array}$ & Acceptability judgment task & Behavioral \\
\hline 5 & $\begin{array}{l}\text { Chunpeng and } \\
\text { Hee-Don, } 2017\end{array}$ & 40 & 20 & 20 & $\begin{array}{l}\text { Late Chinese-Korean bilinguals and } \\
\text { Chinese monolinguals }\end{array}$ & Chinese-Korean & Sentence production & Composition task & Behavioral (errors) \\
\hline 6 & $\begin{array}{l}\text { Dragoy et al., } \\
2019\end{array}$ & 60 & 30 & 30 & $\begin{array}{l}\text { Early and late Russian-German } \\
\text { bilinguals and Russian monolinguals }\end{array}$ & Russian-German & $\begin{array}{l}\text { Sentence } \\
\text { comprehension }\end{array}$ & $\begin{array}{l}\text { Grammaticality Judgment } \\
\text { test }\end{array}$ & Behavioral (ACC) \\
\hline 7 & Gürel, 2015 & 54 & 27 & 27 & $\begin{array}{l}\text { Early Turkish-English bilinguals and } \\
\text { Turkish monolinguals }\end{array}$ & Turkish-English & $\begin{array}{l}\text { Sentence } \\
\text { comprehension }\end{array}$ & Acceptability judgment task & Behavioral (AR) \\
\hline 8 & $\begin{array}{l}\text { Kaltsa et al., } \\
2015\end{array}$ & 91 & 25 & 18 & $\begin{array}{l}\text { Late Greek-Swedish bilinguals and } \\
\text { Greek monolinguals }\end{array}$ & Greek-Swedish & $\begin{array}{l}\text { Sentence } \\
\text { comprehension }\end{array}$ & $\begin{array}{l}\text { Self-paced listening } \\
\text { sentence-picture matching } \\
\text { task }\end{array}$ & $\begin{array}{l}\text { Behavioral (RT and } \\
\text { ACC) }\end{array}$ \\
\hline 9 & $\begin{array}{l}\text { Laufer and } \\
\text { Baladzhaeva, } \\
2015\end{array}$ & 81 & 44 & 21 & $\begin{array}{l}\text { Late Russian-Hebrew bilinguals and } \\
\text { Russian monolinguals }\end{array}$ & Russian-Hebrew & $\begin{array}{l}\text { Sentence } \\
\text { comprehension }\end{array}$ & $\begin{array}{l}\text { Grammaticality judgment } \\
\text { task }\end{array}$ & Behavioral (AR) \\
\hline 10 & $\begin{array}{l}\text { Liceras and } \\
\text { Senn, } 2009\end{array}$ & 44 & 12 & 20 & $\begin{array}{l}\text { Late Spanish-English bilinguals and } \\
\text { Spanish monolinguals }\end{array}$ & Spanish-English & $\begin{array}{l}\text { Sentence } \\
\text { comprehension }\end{array}$ & $\begin{array}{l}\text { Acceptability judgment } \\
\text { task; Clitic-triggered } \\
\text { attachment }\end{array}$ & Behavioral (AR) \\
\hline 11 & $\begin{array}{l}\text { Ribbert and } \\
\text { Kuiken, } 2010\end{array}$ & 90 & 52 & 38 & $\begin{array}{l}\text { Late German-Dutch bilinguals and } \\
\text { German monolinguals }\end{array}$ & German-Dutch & $\begin{array}{l}\text { Sentence } \\
\text { comprehension }\end{array}$ & $\begin{array}{l}\text { Grammaticality judgment } \\
\text { task }\end{array}$ & Behavioral (errors) \\
\hline 12 & $\begin{array}{l}\text { Ribes and } \\
\text { Llanes, } 2015\end{array}$ & 35 & 15 & 20 & $\begin{array}{l}\text { Late English-Spanish bilinguals and } \\
\text { English monolinguals }\end{array}$ & English-Spanish & $\begin{array}{l}\text { Sentence and lexical } \\
\text { production }\end{array}$ & $\begin{array}{l}\text { Storytelling test; C-Cloze } \\
\text { test }\end{array}$ & $\begin{array}{l}\text { Behavioral (pauses } \\
\text { and FO) }\end{array}$ \\
\hline 13 & $\begin{array}{l}\text { Román et al., } \\
2015\end{array}$ & 33 & 16 & 17 & $\begin{array}{l}\text { Early Spanish-Catalan bilinguals and } \\
\text { Spanish monolinguals }\end{array}$ & Spanish-Catalan & $\begin{array}{l}\text { Sentence } \\
\text { comprehension }\end{array}$ & Acceptability judgment & Behavioral (ACC) \\
\hline 14 & Schmid, 2014 & 126 & 53 & 53 & $\begin{array}{l}\text { Late German-English bilinguals, English } \\
\text { learners of German and German } \\
\text { monolinguals }\end{array}$ & German-English & Sentence production & $\begin{array}{l}\text { Spontaneous speech } \\
\text { sampling }\end{array}$ & Behavioral (ACC) \\
\hline 15 & $\begin{array}{l}\text { Schmitz et al., } \\
2016\end{array}$ & 53 & I/G: 10; S/G: 8 & I: 10; S: 7 & $\begin{array}{l}\text { Late Italian-German bilinguals, late } \\
\text { Spanish-German bilinguals, Spanish } \\
\text { monolinguals, and Italian monolinguals }\end{array}$ & $\begin{array}{l}\text { Italian-German; } \\
\text { Spanish-German }\end{array}$ & Sentence production & $\begin{array}{l}\text { Spontaneous speech } \\
\text { sampling }\end{array}$ & Behavioral (FO) \\
\hline 16 & $\begin{array}{l}\text { Tsimpli et al., } \\
2004\end{array}$ & 79 & I/E: 20; G/E: 19 & I: 20; G: 20 & $\begin{array}{l}\text { Late Italian-English bilinguals, late } \\
\text { Greek-English bilinguals, Italian } \\
\text { monolinguals, and Greek monolinguals }\end{array}$ & $\begin{array}{l}\text { Italian-English/Greek- } \\
\text { English }\end{array}$ & $\begin{array}{l}\text { Sentence production } \\
\text { and comprehension }\end{array}$ & $\begin{array}{l}\text { Headlines task; picture } \\
\text { verification task }\end{array}$ & Behavioral (FO) \\
\hline
\end{tabular}

Groups within studies that do not meet the criteria are not included in the table.

Bilingual sample size: E/R, English and Russian speakers; R/E, Russian and English speaker; LB, late bilingual; EB, early bilinguals; I/G, Italian and German speakers; S/G, Spanish and German speakers; I/E, Italian and English speakers; G/E, Greek and English speakers.

Monolingual sample size: E, English speakers; R, Russian speakers; I, Italian speakers; S, Spanish speakers; G, Greek speakers.

Measures: RT, reaction times; $A C C$, accuracy; AR, acceptability ratings; FO, frequency of occurrence. 


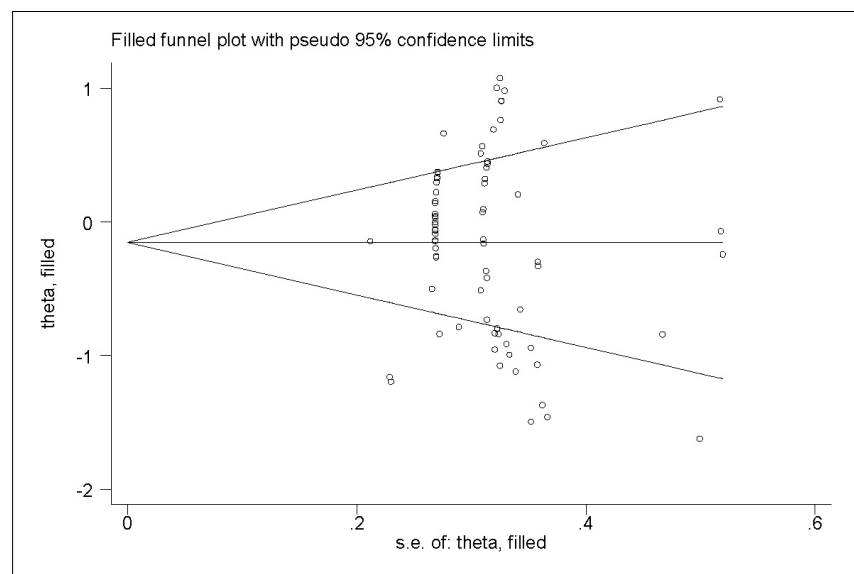

FIGURE 2 | Funnel plot.

12, 14 and 15). One study collected data from both sentence production and comprehension (study 16). All studies used behavioral measures.

\section{Differences Between Bilinguals and Monolinguals in L1}

The meta-analysis was calculated based on 81 effect sizes reported in 14 articles. The pooled SMD was -0.155 (95\% CI, -0.301 to $-0.009 ; p<0.001)$. There was substantial heterogeneity across studies $\left(I^{2}=79.1 \% ; 95 \% \mathrm{CI}, 74 \%\right.$ to $\left.83 \%\right)$, and it reached significance $\left(Q_{80}=382.99 ; p<0.001\right)$. These results showed a statistically significant difference between monolinguals and bilinguals in L1 morphosyntactic processing, and according to Cohen's proposal, the effect size was small.

\section{Publication Bias}

Results of the Egger's test (bias, $-0.907 ; 95 \%$ CI, -4.082 to 2.268; $p=0.571)$ and Begg and Mazumdar's test $(z=1.02 ; p<0.314)$ indicated no publication bias. The Duval and Tweedie procedure did not impute any missing studies, and the SMD did not change [SMD, -0.155 ; $(95 \% \mathrm{CI},-0.301$ to -0.009$) ; p<0.038]$. As a result, there is no evidence of publication bias. The funnel plot is shown in Figure 2.

\section{Sensitivity Analysis}

The pooled SMD based on the 81 effect sizes revealed little change when Cohen's $d$ [SMD, -0.157 (95\% CI, -0.305 to $-0.008 ; p=0.039)$ ] and the fixed-effects model [SMD, $-0.144(95 \% \mathrm{CI},-0.210$ to $-0.078 ; p=0.000)]$ were used. The effect size remains small in both cases, and the differences between monolingual and bilingual speakers remain statistically significant. If studies on morphological processing were independently subject to analyses, the SMD increased considerably, and the differences between monolingual and bilingual speakers remain statistically significant [SMD, -0.882 (95\% CI, -1.167 to $-0.598 ; p<0.001)$ ]. However, when studies on syntactic processing [SMD, -0.011 (95\% CI, -0.155 to 0.133 ; $p=0.879)$ ], comprehension tasks [SMD, -0.165 (95\% CI, -0.339 to $-0.008 ; p=0.061)$, and production tasks [SMD, $-0.124(95 \%$
CI, -0.397 to $0.148 ; p=0.372)$ ] were analyzed separately, the SMD varied with no significant differences between monolingual and bilingual groups. Table 2 summarizes the results of the sensitivity analysis.

\section{Subgroup Analysis}

Table 3 depicts the results for the subgroup analysis. The studies that did not report information about some of the variables of interest (AoA, immersion context, immersion duration, modality of presentation, structure similarity) comprised a no-information group included in the corresponding subgroup analysis to explore their role in the outcome.

We inspected subgroups associated with characteristics of bilingual experience. There were statistically significant differences between subgroups investigating early, late bilinguals, and a no-information group $\left(Q_{2}=18.05, p<0.001\right)$ with greater effect sizes observed in studies without information related to AoA $(k=11)$, while studies including late AoA $(k=45)$ presented a greater effect compared to those comprised of bilinguals with early acquisition of the L2 $(k=25)$. However, none of the individual effects in each group was significant (all $p$ 's $>0.05$ ). When considering immersion, no differences appeared between articles exploring bilinguals immersed in their L1 $(k=1)$ and those exploring bilinguals immersed in their L2 $(k=80)$, but this last group of studies presented a significant effect size $(p=0.035)$. Finally, when looking at LoR in the L2 environment, we found statistically significant differences between short and long LoR studies $\left(Q_{1}=17.76, p<0.001\right)$, and the effect was significant in the short LoR $(k=2)$, but it did not reach significance in the long LoR subgroup $(k=79 ; p=0.080)$.

Exploration of the similarity of the structures between languages revealed that effect sizes significantly differed when we compared studies using similar and dissimilar features between languages (similar, dissimilar, collapsed, n/a, and no-information, $\left.Q_{4}=109.21, p<0.001\right)$, but differences between monolinguals and bilinguals were not significant in the group of studies that used either similar or dissimilar structures. As seen in Table 3, effect sizes were larger if the languages' characteristics were collapsed $(k=1)$.

Investigating the modality of stimuli presentation, research dealing with auditory, visual, and audiovisual material did not significantly differ between modalities, and the effect size was statistically significant only in the group with visual presentation $(k=42 ; p=0.043)$.

\section{Meta-Regression}

Meta-regression analyses with RVE (Hedges et al., 2010; TannerSmith and Tipton, 2014) were performed. We considered the effect of each continuous moderator individually (LoR, L2 proficiency, or L2-AoA; bivariate meta-regression) over the $\mathrm{SMD}$, and the results indicated a significant difference in the effect size magnitude associated with LoR $(\beta=0.040$ [95\% CI, 0.013 to 0.066$] ; p<0.016)$. However, according to TannerSmith et al. (2016), the p-value was untrustworthy because the degrees of freedom were less than four. No significant differences were observed for proficiency in L2 and L2-AoA variables (see Table 4). 
TABLE 2 | Sensitivity analysis.

\begin{tabular}{lccccc}
\hline Analysis & No. of effect sizes $(\mathbf{k})$ & SMD & $\mathbf{9 5 \%} \mathbf{C l}$ & $\boldsymbol{p}$ & $\left.\mathbf{I}^{\mathbf{2}} \mathbf{( 9 5 \%} \mathbf{C l}\right)$ \\
\hline Effectiveness & 81 & -0.155 & -0.301 to -0.009 & 0.038 & $79.1 \%(74 \%-83 \%)$ \\
Cohen's $d$ test & 81 & -0.157 & -0.305 to -0.008 & 0.039 & $79.02 \%(74 \%-83 \%)$ \\
Fixed effect model & 81 & -0.144 & -0.210 to -0.078 & $<0.001$ & $79.1 \%(74 \%-83 \%)$ \\
Including comprehension task studies only & 59 & -0.165 & -0.339 to 0.008 & 0.061 & $81.1 \%(76 \%-85 \%)$ \\
Including production task studies only & 22 & -0.124 & -0.397 to 0.148 & 0.372 & $72.1 \%(57 \%-82 \%)$ \\
Including syntactic processing studies only & 68 & -0.011 & -0.155 to 0.133 & 0.879 & $73.8 \%(67 \%-79 \%)$ \\
Including morphological processing studies only & 13 & -0.882 & -1.167 to -0.598 & $<0.001$ & $67.8 \%(43 \%-82 \%)$ \\
\hline
\end{tabular}

TABLE 3 | Subgroup analysis.

\begin{tabular}{|c|c|c|c|c|c|c|}
\hline Subgroup analysis & No. of effect sizes ( $k$ ) & SMD & $95 \% \mathrm{Cl}$ & $\boldsymbol{p}^{\dagger}$ & $I^{2}$ & Between-group heterogeneity ${ }^{\ddagger}$ \\
\hline Comprehension & 59 & -0.165 & -0.339 to 0.008 & 0.061 & $81.1 \%$ & $Q_{1}=0.46, p=0.500$ \\
\hline \multicolumn{7}{|c|}{ AOA (type of bilingualism) } \\
\hline Early bilingualism & 25 & 0.022 & -0.103 to 0.147 & 0.734 & $26.2 \%$ & $Q_{2}=18.05, p<0.001$ \\
\hline Late bilingualism & 45 & -0.193 & -0.424 to 0.038 & 0.102 & $83.5 \%$ & \\
\hline \multicolumn{7}{|l|}{ Context } \\
\hline Immersed in L1 & 1 & 0.206 & -0.462 to 0.874 & 0.545 & - & $Q_{1}=1.06, p=0.302$ \\
\hline Immersed in L2 & 80 & -0.159 & -0.307 to -0.012 & 0.035 & $79.3 \%$ & \\
\hline \multicolumn{7}{|l|}{ LoR } \\
\hline Short & 2 & -1.148 & -1.798 to -0.498 & 0.001 & $48.6 \%$ & $Q_{1}=17.76, p<0.001$ \\
\hline Long & 79 & -0.130 & -0.276 to 0.016 & 0.080 & $78.5 \%$ & \\
\hline Audiovisual & 16 & 0.005 & -0.262 to 0.272 & 0.970 & $65.5 \%$ & \\
\hline \multicolumn{7}{|c|}{ Structure congruence } \\
\hline Different & 43 & -0.134 & -0.294 to 0.027 & 0.103 & $67.8 \%$ & $Q_{4}=109.21, p<0.001$ \\
\hline Similar & 25 & 0.190 & -0.053 to 0.434 & 0.125 & $75.8 \%$ & \\
\hline Not applicable & 5 & -1.054 & -1.405 to -0.703 & 0.001 & $21.0 \%$ & \\
\hline Collapsed & 1 & -1.163 & -1.611 to -0.715 & 0.001 & - & \\
\hline No information & 7 & -0.751 & -1.348 to -0.154 & 0.014 & $84.7 \%$ & \\
\hline
\end{tabular}

${ }^{\dagger}$ Significance tests in which for each subgroup, the null hypothesis is that $S M D=0$.

$\ddagger_{Q}$-values represent the comparison of subgroup means based on a chi-square distribution in which the null hypothesis is that the effect size is the same for all subgroups.

When the effect of all covariates (LoR and L2-AoA) were considered simultaneously (multivariate meta-regression) in the same RVE meta-regression model, LoR and age of acquisition did not predict the effect size magnitude. L2 proficiency had to be excluded from the analysis due to missing values.

\section{DISCUSSION}

The work presented here addresses the changes that the native language undergoes as a consequence of contact with a second language in bilinguals. Our aim was twofold: we wanted to explore circumstances that lead to variations in the L1 and find a connection between the explanatory accounts of bilingual/monolingual differences in native processing and the data. To do so, we employed a systematic review and metaanalysis of research in sentence comprehension and production comparing monolingual and bilingual performance. Next, we summarize our results, and then we will try to link them with cognitive processes that might be behind changes in the native processing of sentences.

The systematic review comprised 16 studies, and 14 were used in the meta-analysis. Overall, results showed that individuals who speak more than one language were subject to variations in their native tongue with a small and significant effect size. As we strove to tell apart L1 changes connected to the main facets of bilingual sentence processing, subgroups analyses were used. No differences were observed between comprehension and production, and importantly, if analyses considered each group of studies separately, monolinguals and bilinguals did not display different behavior. Regarding the bilingual experience, differences were statistically significant in studies that compared monolinguals to bilinguals immersed in their L2 and bilinguals with a short LoR in a context 
TABLE 4 | Coefficient statistics of meta-regression analysis with RVE estimates on the association between SMD and other covariates.

\begin{tabular}{|c|c|c|c|}
\hline & Beta & $95 \% \mathrm{Cl}$ & $p$ \\
\hline \multicolumn{4}{|c|}{ Bivariate meta-regression } \\
\hline LoR & 0.040 & 0.013 to 0.066 & 0.016 \\
\hline Proficiency in L2 & 0.050 & -0.474 to 0.574 & 0.730 \\
\hline AoA & -0.001 & -0.050 to 0.050 & 0.964 \\
\hline \multicolumn{4}{|c|}{ Multivariate meta-regression } \\
\hline LoR & -0.031 & -0.046 to 0.108 & 0.254 \\
\hline AoA & 0.019 & -0.064 to 0.102 & 0.499 \\
\hline
\end{tabular}

LoR, length of residence; AoA, age of acquisition.

where the second language is spoken. In the meta-analysis regression, the continuous variables L2 proficiency and AoA did not predict the effect size observed in sentence processing; following the subgroups analysis, shorter LoR predicted wider differences between monolinguals and bilinguals in their L1. All in all, these findings suggest that L1 processing may be subject to small, qualitatively different variations across the bilingual experience rather than accumulative (Schmid and Karayayla, 2020; Steinhauer and Kasparian, 2020), and all the factors should be taken into consideration when addressing the patterns of bilingual processing in their native language.

\section{Comprehension and Production Studies}

Sentence production is less explored than comprehension despite the stress that recent approaches give to considering both production and comprehension and its interdependence to feed language models (Pickering and Garrod, 2013; Dell and Chang, 2014). Our work reflects this trend in research, with a higher number of studies targeting comprehension.

Within comprehension, most of the reviewed studies used acceptability/grammaticality judgments (12 studies; 10 included in the meta-analysis, see Table 1). In an investigation by Schmid and Dusseldorp (2010), German monolinguals outperformed German-English bilinguals and German-Dutch bilinguals in verbal fluency, the C-test, and a film re-telling task; however, their behavior was similar in an auditorily grammatical judgment task. Although their results may reveal stable L1 knowledge at this linguistic skill in bilinguals, the authors do not discard the hypothesis that the sentences could be easy for the readers. Also, the use of brain markers as participants read sentences may reveal differences that the offline acceptability judgments do not, even in low complexity sentences (see Román et al., 2015). For example, Italian-English bilinguals and Italian monolinguals in Kasparian et al. (2017) had to rate the grammaticality of eight-word sentences in Italian that could include local or non-local agreement violations while neurophysiological activity was recorded (for example, "Il lavatore torna dalla fabbrica sporco di grasso," The workers plural $_{\text {returns }}$ singular from the factory dirty $_{\text {singular }}$ with grease). They did not find a group effect or group interaction at the acceptability ratings, but groups differed in reaction times and the neurophysiological patterns. Together with neurophysiological methodologies, other online measures like eye-tracking or self-paced reading may be more sensitive than offline acceptability judgments to catch differences between groups (e.g., self-paced listening, Kaltsa et al., 2015, in our review; for a deeper discussion on online measures in the field, see Marinis, 2003; Roberts, 2012). The prevalence of the acceptability-ratings task and behavioral measures within our sample of studies might be behind the lack of a subgroup effect.

Research dealing with sentence production, on the other hand, employed spontaneous speech/writing sampling (speech, Schmid, 2014; Schmitz et al., 2016; writing, Chunpeng and Hee-Don, 2017), storytelling (Ribes and Llanes, 2015), and a headlines task, which provides a verb, a noun phrase and an adverbial expression that participants have to use to produce a sentence describing a picture (Tsimpli et al., 2004). When present, differences in these studies showed that bilinguals tended to be slower and employed syntactical structures that were permitted in their L1 but preferred in their L2, suggesting that variation, rather than attrition or loss is a term better suited for L1 changes in individuals that speak more than one language (Schmid, 2014; Schmitz et al., 2016). Although a separate analysis of bilinguals vs. monolinguals in sentence production studies did not show a significant effect size, the production pattern reveals co-activation and transfer of L2 features in the bilingual grammar, as we will explain later.

\section{Bilingual Experience}

The magnitude of effect sizes differed between groups within AoA, and LoR, as seen in the subgroups analysis, but were only statistically significant when looking at studies that included immersion in L2 and short LoR. Nevertheless, LoR was the only continuous variable predicting differences between monolinguals and bilinguals in the bivariate meta-regression. In Schmid and Dusseldorp's (2010) study mentioned above, one of their objectives was investigating variables that predicted L1 attrition. Only LoR predicted attrition in free speech (in lexical diversity and errors) using a film re-telling task. Some articles in the present review that did not investigate the relation of attrition with LoR used a similar procedure. For example, Schmid (2014) had a subgroup of 20 late German/English bilinguals with a minimum LoR in Canada of 9 years but up to four decades (mean and standard deviation not provided) that did not differ from their monolingual peers in morphosyntactic variables. In our meta-regression, lower LoR is associated with larger differences between bilinguals and monolinguals and grants the need for further research, including an earlier (and shorter) range of LoR in sentence production.

More recently, Schmid and Karayayla (2020) explored the role of LoR in comprehension. They collected sentence production data from 92 Turkish-English bilinguals (collapsed including heritage speakers and therefore excluded from our review and meta-analysis) about their L1 maintenance and acquisition within a wide range of age at onset of bilingualism (AaO; from birth to adulthood). The data indicated that LoR predicted morphosyntactic complexity in L1, but in a direction opposite to our results, the longer the residence in a context where the second language is used, the lower the proficiency in L1. Importantly, they observed that the effects were more evident in early than late bilinguals. Because in the present work 11 of the 14 studies included late bilinguals, it is necessary to assume that variations 
in the L1 are qualitatively different between bilingual experiences and likely the result of different cognitive processes.

In spite of that, the continuous variables LoR, L2 proficiency, and AoA did not predict variation in the L1 in the multivariate meta-regression. One potential explanation is that bilinguals can use cues of different nature to compensate for differences, masking the effect of the variables of interest at the behavioral level examined here. For example, in a study collecting neurophysiological data, Kasparian and Steinhauer (2017) used an acceptability judgment task in Italian with relative clause structures that could be temporarily ambiguous (garden-path as in "Il poliziotto che i ladri arresta registra i nomi," The policeman that the thieves arrests registers the names). The sentences were grammatical in Italian, but some were ungrammatical in English (as in the example) and less preferred garden-path structures in Italian. As expected, bilinguals found the grammatical sentences in Italian but ungrammatical in English as less acceptable than monolinguals. Moreover, the authors predicted a P600 in both groups (greater in bilinguals) to the verb in the relative clause (arresta), commonly found in garden-path sentences as an index of syntactic difficulty, and an N400 related to difficulties in semantic integration because they introduced strong semantic cues (policeman-thieve-arrest) that did not conflict with the structure. Italian monolinguals, which rely more on semantic information, evinced an N400, while the bilinguals did not show this component but a greater P600, as anticipated if they used, like English monolinguals, the strict word order preferably than semantic cues.

One problem in our study that may prevent us from finding a stronger impact of L2 proficiency is using the bilingual term and the collection of L2 proficiency data broadly to cover as many studies as possible. Some authors have warned about the implications that the way we conceive, and measure bilingualism have on the diversity of outcomes we obtain in our growing field of knowledge (Green and Abutalebi, 2013; Luk and Bialystok, 2013; Ooi et al., 2018; Anderson et al., 2020; Kremin and ByersHeinlein, 2021). In the pool of articles reviewed here, proficiency tests go from subjective reports, including those with questions about how much effort it takes to use a language (Liceras and Senn, 2009), to objective measures and placement tests (for example, TOEFL for English proficiency, Chang, 2009; Gürel, 2015; telc for Turkish, Arslan et al., 2015). In addition, some works did not contain proficiency information (e.g., Kaltsa et al., 2015), or provided ranges (e.g., Bylund and Ramírez-Galan, 2014). Under such circumstances, there was enough data to consider proficiency as a categorical variable but impeded the continuous data to be used as recommended for the metaregression (Bialystok, 2018; De Cat et al., 2018; Gunnerud et al., 2020).

\section{Connection to Explanatory Accounts}

As mentioned in the introduction, researchers have considered three leading causes behind the patterns observed in bilingual L1 processing: language co-activation in bilinguals, cross-linguistic transfer, and a reduced frequency of L1 use (Costa and SebastiánGallés, 2015; Cunnings, 2017a; Schmid and Köpke, 2017).

Cunnings (2017a) proposes that retrieval

comprehension. Retrieval interference appears because working memory is a capacity-limited entity (Baddeley, 2013), and coactivation of languages increases the demands when bilinguals have to select one representation from those retrieved from longterm memory and integrate it with the incoming information. In agreement with this idea, Chunpeng and Hee-Don (2017) tested Chinese/Korean bilinguals reporting the use of both languages daily, and therefore more prone to co-activation. Their sample presented difficulties retrieving words in written composition and spent a longer time completing the task compared to Chinese monolinguals. Apart from that, in their research, grammar differences were mainly related to transfer from their L2 (Korean word order, punctuation, among others), similar to English/Spanish bilinguals in Ribes and Llanes (2015) that produced more subordinate constructions allowed in English but preferred in Spanish, and more pauses. Bilinguals may then become "opportunistic" speakers under co-activation contexts selecting representations that alleviate their cognitive load and languages cooperate rather than interfere (Beatty-Martínez et al., 2020).

A prediction derived from the above is that similarities across languages may influence bilingual processing, increasing co-activation, interfering or facilitating processing, or making bilinguals opting for the common structures in sentence processing. However, we have not observed differences between groups with similar and dissimilar structures, and none of the analyses that independently tested similarity and dissimilarity in bilingual vs. monolingual performance was significant. In this respect, co-activation might happen not only when the use of specific structures sharing properties across languages spread activation to nodes in the L2, but also when using the L1 in broader contexts such as L2 immersion (as seen confirmed in the meta-analysis) or when co-activation is locally induced (e.g., watching a movie in the L2; Elston-Güttler et al., 2005). This indicates that any context that prompts co-activation may increase the chances of altered processing even in the absence of shared properties.

In association with this idea, Green and Abutalebi (2013) proposed the adaptive control hypothesis. According to this approach, bilinguals find themselves in different contexts, and each posits specific demands to which the reader/speaker adapts. That is, bilinguals' L1 (and L2) is not only subject to differences in the long run but varies depending on the demands of the environment (e.g., the accent of the interlocutor, unilingual workplace, bilingual community, discourse complexity, etc.). Whenever co-activation creates competition between language schemas, there will be a need for processes that handle interference and select the desired linguistic representations (Green and Abutalebi, 2013). Such processes, on the one hand, use limited resources that may be unavailable for efficient processing (Perfetti and Stafura, 2014; Li and Clariana, 2019) and, on the other hand, make competing representations less accessible through inhibition (e.g., Levy et al., 2007). These processes engaged in controlling interference might explain the direction of LoR effects in our data; at short LoR, the native language is dominant in late bilinguals and L2 usage is expected to trigger inhibitory processes to overcome the interference and facilitate retrieval of the weaker L2 representations. When 
bilinguals try to retrieve their L1 later, it takes time to access the suppressed representations in the L1. As asymmetry between languages decreases, inhibition is no longer needed (Levy et al., 2007).

Also, predictions from this approach are that reading and producing sentences will show either an impairment (for example, an increasing number of pauses, reduced processing speed) or compensation (for example, using simpler structures, using a limited number of cues, repetition of more accessible structures). As discussed earlier, bilinguals in some of the studies reviewed here present more pauses and longer time to produce written or verbally sentences in their L1 (Ribes and Llanes, 2015; Chunpeng and Hee-Don, 2017). Additionally, it is expected that bilinguals (and monolinguals) will have to overcome coactivation and inhibition, and that succeeding in doing so must be more difficult in constructions that demand resources allocation, such as complex grammatical forms (e.g., evidentiality marking in Turkish, Arslan et al., 2015) or pronominal referential relations in sentence comprehension ( $\mathrm{Li}$ and Clariana, 2019). In fact, pronominal resolutions have been studied in the context of language attrition, considering that difficulties in this type of structure may arise due to the need to coordinate different interfaces (grammatical and discourse information; Sorace, 2011; Chamorro et al., 2015). Giving support to this view, we have found research in which bilinguals do not have a strong preference toward a pronominal assignment in the presence of more than one antecedent noun as monolinguals have (Kaltsa et al., 2015; Castro et al., 2017; but see Liceras and Senn, 2009; Schmitz et al., 2016) and show preferences that place less cognitive demands on the reader (low-attachment in L1 in both English-Spanish and Spanish-English bilinguals, Dussias, 2003, 2004), thereby supporting the notion of bilinguals as strategists that adapt to the requirements of their linguistic and cognitive context.

Another factor that may alter L1 processing is the crosslinguistic transfer (Costa and Sebastián-Gallés, 2015). In this regard, we have seen that bilinguals show in their L1 a bias to structures and interpretations that appear frequently in their L2 (examples in production are Ribes and Llanes, 2015; Chunpeng and Hee-Don, 2017; in comprehension, Dussias and Sagarra, 2007). Changes in the L1 sentence processing can appear as a lack of preference for both L1 and L2 biases too, similar to what Kaltsa et al. (2015) and Castro et al. (2017) observed. Specifically, in two experiments, Kaltsa et al. (2015) employed a self-paced listening task with a sentence-picture matching to test pronoun

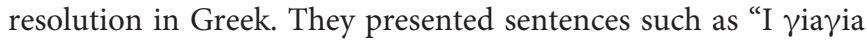
xeretise tin kopela otan afti pernuse to Sromo" (The old lady greeted the girl when she crossed the street) where the antecedent of the overt pronoun in the subordinate clause "afti" (she) could be the subject (old lady) or the direct object (the girl). In Greek, the null subject is the default, and the subject antecedent is preferred under such conditions, while a non-subject antecedent (the girl in the example) is preferred in overt subject pronoun as the one in the example. In this research, Greek-Swedish bilinguals with long LoR were expected to choose more subject antecedents in overt pronoun conditions than monolinguals, but their performance should be similar in null pronoun conditions (Swedish is a non-null subject language). Monolinguals showed differences between null and overt pronoun conditions, but bilinguals did not. Despite this outcome, Kaltsa and colleagues consider that cross-linguistic transfer is not causing their results because a group of older monolinguals presented a performance closer to bilinguals.

Finally, a frequency-based account highlights a reduced L1 input that weakens and biases activation toward L2 properties (Gollan et al., 2005). One way to explore this effect would have been to include relative frequency of use across languages in our analyses, but only a few had information about it (Liceras and Senn, 2009; Castro et al., 2017), and they did not explore its impact. Immersion length may switch the frequency balance between L1 and L2, and studies exploring parsing preferences that differ across languages are helpful since language biases may progressively shift with exposure. However, the results in our meta-regression with shorter LoR showing larger effects say otherwise. In two studies, Spanish-English bilinguals with long L2 immersion (Dussias and Sagarra, 2007) and SpanishEnglish bilinguals with shorter L2 immersion (Dussias, 2004) but similar proficiency change from L1 to L2 preferences while highly proficient Spanish-English bilinguals immersed in their L1 maintained the monolingual routines (Dussias and Sagarra, 2007). Such results could suggest that frequency-related modifications occur rapidly and appear in readers with shorter exposure to L2 but also that there is more than one mechanism underlying variations across bilingual groups in agreement with evidence that shows a non-linear L1 variation (Schmid and Karayayla, 2020). Other processes such as the need for L1 inhibition in an L2 setting cannot be ruled out, and ERPs studies point to a more significant role of competition in grammar differences instead of a reduced frequency in L1, at least in the early stages of immersion in an L2 context (for a review, see Steinhauer and Kasparian, 2020).

Although these explanations do not exclude each other and may act simultaneously, they do predict different outcomes under different conditions. Therefore, more research is necessary to separate their respective effects and the relative weight they have on bilinguals' L1 at several stages and situations.

\section{CONCLUSION}

To sum up, learning an L2 involves mutual influence between languages that vary qualitatively and quantitatively across time and experience, most likely in response to differences in demands of the environment and the cognitive processes recruited to deal with them.

In the present work, we targeted morphosyntactic processing. Some researchers consider that attrition occurs mainly at the lexical level in comprehension and production and that when grammatical rules are concerned, it affects aspects related to lexical retrieval (Schmid and Fägersten, 2010). Nonetheless, we have observed that bilingual deviations from monolinguals are evident though small in morphosyntax, even in individuals immersed in their second language but without knowledge in their L2 (Laufer and Baladzhaeva, 2015). It is important to note that studies targeting morphosyntax often imply the interplay 
of distinct linguistic subskills, as seen above in Kasparian and Steinhauer (2017), where semantic constraints influence bilingual parsing of garden-path sentences. Experimental designs that dissociate effects across linguistic levels will help to clarify differences in the processes subserving L2 influences in the L1.

Other variables not addressed here may influence the cognitive processes involved in sentence processing, resulting in differences between monolinguals and bilinguals in their native language. The two reasons behind this absence are the lack of consistency in gathering such data among studies and selecting contrasts between monolinguals and bilinguals instead of different groups within bilinguals. Further research will need to attend to these variables. For example, none of the experiments reviewed collected data about individual differences in either cognitive control (conflict detection, inhibition, cognitive flexibility, or task switching) or working memory, which impeded directly testing the association of cognitive resources in dealing with language co-activation. Besides, here the target contrast was comparing bilinguals to monolinguals. Hopp and Schmid (2013) warned of the difficulties that using monolinguals as a reference group entails, given that the mere existence of two languages in the bilingual mind provides a qualitatively different ground. In this sense, it seems more appropriate to compare early and late bilinguals who reach similar proficiency or investigate individual differences while matching bilingual experience. While we acknowledge the validity of Hopp and Schmid's statement, we consider that there is a value in our work to address the distinct mechanisms involved in dealing with two languages and their relation with several aspects of the bilingual experience.

Apart from the above, the results presented require cautious interpretation. Although data dependence was controlled in the meta-regression analysis with RVE (Hedges et al., 2010; Tanner-Smith and Tipton, 2014), subgroups analyses, sensitivity, and main effect analyses did not control it. Besides that, we did not assess the risk of bias of the included studies. Aside from the methodological limitations, reported/collected information regarding the bilingual experience was quite heterogeneous across studies what prevented us from having a more extensive and detailed exploration of factors impacting language processing.

Despite these limitations, the present work followed the PRISMA guidelines; thus, the search of the studies was carried out in the most relevant databases using a wide variety of terms without restrictions regarding the year of publication or language, giving the systematic review and meta-analysis a high sensitivity. Additionally, two independent researchers went through the entire screening process, selection, and extraction of the characteristics. Last but not least, there was no evidence of publication bias, and we analyzed sensitivity, which contributes to the robustness of the results found.

Finally, some recommendations can be derived from our work. Methodologically speaking, offline measures, when used, should be accompanied by online measures that provide more sensitivity and information regarding the cognitive processes involved. In addition, because sentence processing implies the interaction of several types of information, the inclusion of conditions that allow isolating the influence of independent variables is encouraged. Regarding the target population, the study of cross-linguistic influence requires (1) a clear definition of terms like "proficiency"; (2) detailed data collection of measures and experience with both languages to have a profile that considers the balance between L1 and L2, and (3) going beyond monolinguals as a group of reference and consider bilingual groups that differ in several dimensions to explore the variables that affect changes in the L1.

\section{DATA AVAILABILITY STATEMENT}

The original contributions presented in the study are included in the article/Supplementary Material, further inquiries can be directed to the corresponding author.

\section{AUTHOR CONTRIBUTIONS}

PR conceived the study. PR and IG-G prepared the strategy search, conducted the systematic literature search, screened studies for eligibility together with Laura Giraldo and Raquel Román, extracted data, contributed to the manuscript preparation, and approved the final version. IG-G conducted the statistical analyses. Both authors contributed to the article and approved the submitted version.

\section{FUNDING}

This research was financially supported by grants from the Spanish Ministry of Science, Innovation, and Universities (Fondos FEDER) and the Andalusian Government (PGC2018093506-B-I00 and PY18-FR-0007).

\section{ACKNOWLEDGMENTS}

The authors would like to thank Laura Giraldo and Raquel Román for their assistance.

\section{SUPPLEMENTARY MATERIAL}

The Supplementary Material for this article can be found online at: https://www.frontiersin.org/articles/10.3389/fpsyg. 2022.757023/full\#supplementary-material

\section{REFERENCES}

Ameel, E., Malt, B. C., Storms, G., and van Assche, F. (2009). Semantic convergence in the bilingual lexicon. J. Mem. Lang. 60, 270-290.

Andersen, R. W. (1982). "Determining the linguistic attributes of language attrition," in The loss of language skills, eds R. D. Lambert and B. F. Freed (Rowley, MA: Newbury House), 83-118. 
Anderson, J., Hawrylewicz, K., and Bialystok, E. (2020). Who is bilingual? Snapshots across the lifespan. Bilingual. Lang. Cognit. 23, 929-937. doi: 10.1017/ S1366728918000950

Arslan, S., Bastiaanse, R., and Felser, C. (2015). Looking at the evidence in visual world: eye movements reveal how bilingual and monolingual Turkish speakers process grammatical evidentiality. Front. Psychol. 6:1-13. doi: 10.3389/fpsyg. 2015.01387

Baddeley, A. D. (2013). Essentials of human memory (classic ed.). London: Psychology Press.

Baus, C., Costa, A., and Carreiras, M. (2013). On the effects of second language immersion on first language production. Acta Psychol. 142, 402-409. doi: 10. 1016/j.actpsy.2013.01.010

Beatty-Martínez, A. L., Navarro-Torres, C. A., and Dussias, P. E. (2020). Codeswitching: A Bilingual Toolkit for Opportunistic Speech Planning. Front. Psychol. 11:1699. doi: 10.3389/fpsyg.2020.01699

Beaussart, M. L., Barbarot, S., Mauger, C., and Roy, A. (2018). Systematic review and meta-analysis of executive functions in preschool and school-age children with neurofibromatosis Type 1. J. Int. Neuropsychol. Soc. JINS 24, 977-994. doi: $10.1017 /$ S1355617718000383

Begg, C. B., and Mazumdar, M. (1994). Operating Characteristics of a Rank Correlation Test for Publication Bias. Biometrics 50:1088. doi: 10.2307/2533446

Benmamoun, E., Montrul, S., and Polinsky, M. (2013). Defining an "ideal" heritage speaker: theoretical and methodological challenges Reply to peer commentaries. Theoret. Linguist. 39, 259-294. doi: 10.1515/tl-2013-0018

Bergmann, C., Meulman, N., Stowe, L. A., Sprenger, S. A., and Schmid, M. S. (2015). Prolonged L2 immersion engenders little change in morphosyntactic processing of bilingual natives. NeuroReport 26, 1065-1070. doi: 10.1097/WNR. 0000000000000469

Bernolet, S., Hartsuiker, R. J., and Pickering, M. J. (2007). Shared syntactic representations in bilinguals: Evidence for the role of word-order repetition. J. Exp. Psychol. Learn. Mem. Cognit. 33, 931-949. doi: 10.1037/0278-7393.33.5. 931

Bialystok, E. (2018). "Bilingualism and executive functions: What is the connection?", in Bilingual cognition and language, eds D. Miller, F. Bayram, J. Rothman, and L. Serratrice (Amsterdam: John Benjamins Publishing Company), 283-306. doi: 10.1075/sibil.54.13bia

Bice, K., and Kroll, J. F. (2015). Native language change during early stages of second language learning. NeuroReport 26, 966-971. doi: 10.1097/WNR. 0000000000000453

Bobb, S. C., Von Holzen, K., Mayor, J., Mani, N., and Carreiras, M. (2020), Co-activation of the L2 during L1 auditory processing: An ERP cross-modal priming study. Brain Lang. 203:104739. doi: 10.1016/j.bandl.2019.104739

Borenstein, M., Hedges, L., Higgins, J., and Rothstein, H. (2013). Comprehensive Meta-Analysis Version 3. Englewood: Biostat.

Borenstein, Michael, Higgins, J. P. T., Hedges, L. V., and Rothstein, H. R. (2017). Basics of meta-analysis: I2 is not an absolute measure of heterogeneity. Res. Synth. Methods 8, 5-18. doi: 10.1002/jrsm.1230

Brothers, T., Hoversten, L., and Traxler, M. (2021). Bilinguals on the garden-path: Individual differences in syntactic ambiguity resolution. Bilingual. Lang. Cognit. 24, 612-627. doi: 10.1017/S1366728920000711

Bylund, E., Abrahamsson, N., and Hyltenstam, K. (2010). The role of language aptitude in first language attrition: The case of pre-pubescent attriters. Appl. Linguist. 31, 443-464. doi: 10.1093/applin/amp059

Bylund, E., and Ramírez-Galan, P. (2014). Language Aptitude in First Language Attrition: A Study on Late Spanish-Swedish Bilinguals. Appl. Linguist. 37, 621-638. doi: 10.1093/applin/amu055

Casaponsa, A., Antón, E., Pérez, A., and Duñabeitia, J. A. (2015). Foreign language comprehension achievement: insights from the cognate facilitation effect. Front. Psychol. 6:588. doi: 10.3389/fpsyg.2015.00588

Castro, T., Rothman, J., and Westergaard, M. (2017). On the directionality of cross-linguistic effects in bidialectal bilingualism. Front. Psychol. 8:1-14. doi: 10.3389/fpsyg.2017.01382

Chamorro, G., Sorace, A., and Sturt, P. (2015). What is the Source of L1 Attrition? The Effect of Recent L1 Re-exposure on Spanish Speakers under L1 Attrition. Bilingual. Lang. Cognit. 19, 520-532. doi: 10.1017/S1366728915000152

Chang, C. B. (2012). Rapid and multifaceted effects of second-language learning on first-language speech production. J. Phonetics 40, 249-268. doi: 10.1016/j.wocn. 2011.10.007
Chang, C. B. (2013). A Novelty Effect in Phonetic Drift of the Native Language. J. Phonet. 41, 520-533. doi: 10.1016/j.wocn.2013.09.006

Chang, Y. F. (2009). How to say no: an analysis of cross-cultural difference and pragmatic transfer. Lang. Sci. 31, 477-493. doi: 10.1016/j.langsci.2008.01.002

Cherciov, M. (2011). Between attrition and acquisition: The dynamics between two languages in adult migrants. Dissert. Abstr. Int. Sect. A 73:1761.

Chunpeng, C., and Hee-Don, A. (2017). The Influence of L2 on L1 Lexical Competence and Grammatical Properties in Written Expressions. Chin. J. Appl. Linguist. 40, 181-191. doi: 10.1515/cjal-2017-0011

Clahsen, H., and Felser, C. (2006). How native-like is non-native language processing? Trends Cognit. Sci. 10, 564-570. doi: 10.1016/j.tics.2006.10.002

Cohen, J. (1988). "Statistical Power Analysis for the Behavioral Sciences," in Statistical Power Analysis for the Behavioral Sciences, 2nd Edn, ed. J. Cohen (New Jersey, NJ: Lawrence Earlbaum Associates), doi: 10.4324/9780203771587

Contemori, C., Asiri, O., and Perea Irigoyen, E. D. P. (2019). Anaphora resolution in L2 English: an analysis of discourse complexity and crosslinguistic interference. Stud. Second Lang. Acquisit. 2019, 1-28. doi: 10.1017/ S0272263119000111

Costa, A., and Sebastián-Gallés, N. (2015). How does the bilingual experience sculpt the brain? Nat. Rev. Neurosci. 15, 336-345. doi: 10.1038/nrn3709

Cunnings, I. (2017a). Parsing and working memory in bilingual sentence processing. Bilingual. Lang. Cognit. 20, 659-678. doi: 10.1017/ S1366728916000675

Cunnings, I. (2017b). Interference in Native and Non-Native Sentence Processing. Bilingual. Lang. Cognit. 20, 712-721. doi: 10.1017/S1366728916001243

Daneman, M., and Green, I. (1986). Individual differences in comprehending and producing words in context. J. Mem. Lang. 25, 1-18. doi: 10.1016/0749596x(86)90018-5

de Bot, K., Lowie, W., and Verspoor, M. (2007). A Dynamic Systems Theory approach to second language acquisition. Bilingual. Lang. Cognit. 10, 7-21. doi: $10.1017 / S 1366728906002732$

De Cat, C., Gusnanto, A., and Serratrice, L. (2018). Identifying a threshold for the executive function advantage in bilingual children. Stud. Sec. Lang. Acquisit. 40, 119-151. doi: 10.1017/S0272263116000486

Dell, G. S., and Chang, F. (2014). The P-chain: relating sentence production and its disorders to comprehension and acquisition. Philosop. Transact. R. Soc. B 369:20120394. doi: 10.1098/rstb.2012.0394

Diependaele, K., Duñabeitia, J. A., Morris, J., and Keuleers, E. (2011). Fast morphological effects in first and second language word recognition. J. Mem. Lang. 64, 344-358. doi: 10.1016/j.jml.2011.01.003

Domínguez, L. (2013). Understanding interfaces: Second language acquisition and first language attrition of Spanish subject realization and word order variation. Amsterdam: John Benjamins.

Dragoy, O., Virfel, E., Yurchenko, A., and Bastiaanse, R. (2019). Aspect and tense attrition in Russian-German bilingual speakers. Int. J. Bilingual. 23, 275-295. doi: $10.1177 / 1367006917728388$

Dussias, P. E. (2003). Syntactic ambiguity resolution in second language learners: Some effects of bilinguality on L1 and L2 processing strategies. Stud. Sec. Lang. Acquisit. 25, 529-557. doi: 10.1017/s0272263103000238

Dussias, P. E. (2004). Parsing a first language like a second: The erosion of L1 parsing strategies in Spanish-English Bilinguals. Int. J. Bilingual. 3, 355-371. doi: $10.1177 / 13670069040080031001$

Dussias, P. E., and Sagarra, N. (2007). The effect of exposure on syntactic parsing in Spanish-English bilinguals. Bilingual. Lang. Cognit. 10:101.

Dussias, P. E., Perrotti, L., Carlson, M., and Morales, L. (2016). "Exposure to a second language can change processing routines in the first language," in Paper presented at the International Meeting of the Psychonomic Society, Granada, Spain. May 5-8, (Granada: IMPS).

Duval, S., and Tweedie, R. (2000). Trim and fill: A simple funnel-plot-based method of testing and adjusting for publication bias in meta-analysis. Biometrics 56, 455-463. doi: 10.1111/j.0006-341x.2000.00455.x

Elston-Güttler, K. E., Gunter, T. C., and Kotz, S. A. (2005). Zooming into L2: Global language context and adjustment affect processing of interlingual homographs in sentences. Cognit. Brain Res. 25, 57-70. doi: 10.1016/j.cogbrainres.2005.04. 007

Gollan, T. H., Montoya, R. I., Cera, C., and Sandoval, T. C. (2008). More use almost always a means a smaller frequency effect: Aging, bilingualism, and the weaker links hypothesis. J. Mem. Lang. 58, 787-814. doi: 10.1016/j.jml.2007.07.001 
Gollan, T. H., Montoya, R. I., Fennema-Notestine, C., and Morris, S. K. (2005). Bilingualism affects picture naming but not picture classification. Mem. Cognit. 33, 1220-1234. doi: 10.3758/bf03193224

Green, D. W., and Abutalebi, J. (2013). Language control in bilinguals: The adaptive control hypothesis. J. Cognit. Psychol. 25, 515-530. doi: 10.1080/20445911.2013. 796377

Gunnerud, H. L., ten Braak, D., Reikerås, E. K. L., Donolato, E., and MelbyLervåg, M. (2020). Is bilingualism related to a cognitive advantage in children? A systematic review and meta-analysis. Psychol. Bull. 146, 1059-1083. doi: 10.1037/bul0000301

Gürel, A. (2015). First language attrition of constraints on wh-scrambling: Does the second language have an effect?. Int. J. Bilingual. 19, 75-91. doi: 10.1177/ 1367006913506131

Hatzidaki, A., Branigan, H. P., and Pickering, M. J. (2011). Co-activation of syntax in bilingual language production. Cognit. Psychol. 62, 123-150. doi: 10.1016/j. cogpsych.2010.10.002

Hedges, L. V. (1981). Distribution Theory for Glass's Estimator of Effect size and Related Estimators. J. Educat. Statist. 6, 107-128. doi: 10.3102/ 10769986006002107

Hedges, L. V., Tipton, E., and Johnson, M. C. (2010). Robust variance estimation in meta-regression with dependent effect size estimates. Res. Synth. Methods 1, 39-65. doi: 10.1002/jrsm.5

Hicks, G., and Domínguez, L. (2020). A model for L1 grammatical attrition. Sec. Lang. Res. 36, 143-165. doi: 10.1177/0267658319862011

Higgins, J., and Green, S. (2011). Cochrane Handbook for Systematic Reviews of Interventions Version 5.1.0 [updated March 2011]. Available online at: www.cochrane-handbook.org

Hopp, H., and Schmid, M. S. (2013). Perceived foreign accent in L1 attrition and L2 acquisition: the impact of age of acquisition and bilingualism. Appl. Psycholinguist. 34, 361-394.

Kaan, E., Futch, C., Fernández Fuertes, R., Mujcinovic, S., Álvarez, and De La Fuente, E. (2019). Adaptation to syntactic structures in native and nonnative sentence comprehension. Appl. Psycholinguist. 40, 3-27. doi: 10. 1017/S0142716418000437

Kaltsa, M., Tsimpli, I. M., and Rothman, J. (2015). Exploring the source of differences and similarities in L1 attrition and heritage speaker competence: Evidence from pronominal resolution. Lingua 164, 266-288. doi: 10.1016/j. lingua.2015.06.002

Karayayla, T., and Schmid, M. S. (2019). First language attrition as a function of age at onset of bilingualism: First language attainment of Turkish-English Bilinguals in the United Kingdom. Lang. Learn. 69, 106-142. doi: 10.1111/lang. 12316

Kasparian, K., and Steinhauer, K. (2017). When the second language takes the lead: Neurocognitive processing changes in the first language of adult attriters. Front. Psychol. 8:1-22. doi: 10.3389/fpsyg.2017.00389

Kasparian, K., Vespignani, F., and Steinhauer, K. (2017). First Language Attrition Induces Changes in Online Morphosyntactic Processing and Re-Analysis: An ERP Study of Number Agreement in Complex Italian Sentences. Cognit. Sci. 41, 1760-1803. doi: $10.1111 /$ cogs. 12450

Kaushanskaya, M., and Smith, S. (2016). Do grammatical-gender distinctions learned in the second language influence native-language lexical processing? Int. J. Biling. 20, 30-39. doi: 10.1177/1367006915576830

Kremin, L. V., and Byers-Heinlein, K. (2021). Why not both? Rethinking categorical and continuous approaches to bilingualism. Int. J. Bilingual. 2021:13670069211031986. doi: 10.1177/13670069211031986

Kroll, J. F., Bobb, S. C., and Hoshino, N. (2014). Two languages in mind: Bilingualism as a tool to investigate language, cognition, and the brain. Curr. Direct. Psychol. Sci. 23, 159-163. doi: 10.1177/0963721414528511

Lardiere, D. (2009). Some thoughts on the contrastive analysis of features in second language acquisition. Second Lang. Res. 25, 173-227. doi: 10.1177/ 0267658308100283

Laufer, B., and Baladzhaeva, L. (2015). First language attrition without second language acquisition. ITL 166, 229-253. doi: 10.1075/itl.166.2.02lau

Levy, B. J., McVeigh, N. D., Marful, A., and Anderson, M. C. (2007). Inhibiting your native language: the role of retrieval-induced forgetting during second-language acquisition. Psychol. Sci. 18, 29-34. doi: 10.1111/j.1467-9280.2007.01844.x

Li, P., and Clariana, R. (2019). Reading comprehension in L1 and L2: An integrative approach. J. Neurolinguist. 50, 94-105. doi: 10.1016/j.jneuroling.2018.03.005
Libben, M. R., and Titone, D. A. (2009). Bilingual lexical access in context: Evidence from eye movements during reading. J. Exp. Psychol. 35, 381-390. doi: 10.1037/ a0014875

Liceras, J., and Senn, C. (2009). Linguistic theory and the analysis of minority languages: native, immigrant and heritage Spanish speakers. Lengua Migración Lang. Migrat. 1, 39-74.

Linck, J. A., Kroll, J. F., and Sunderman, G. (2009). Losing access to the native language while immersed in a second language: Evidence for the role of inhibition in second language learning. Psychol. Sci. 20, 1507-1515. doi: 10. $1111 / \mathrm{j} .1467-9280.2009 .02480 . \mathrm{x}$

Luk, G., and Bialystok, E. (2013). Bilingualism is not a categorical variable: Interaction between language proficiency and usage. J. Cognit. Psychol. 25, 605-621. doi: 10.1080/20445911.2013.795574

Macizo, P., Bajo, T., and Martín, M. C. (2010). Inhibitory processes in bilingual language comprehension: Evidence from Spanish-English interlexical homographs. J. Mem. Lang. 63, 232-244. doi: 10.1016/j.jml.2010.04.002

Marinis, T. (2003). Psycholinguistic techniques in second language acquisition research. Sec. Lang. Res. 19, 144-161. doi: 10.1191/0267658303sr217ra

Misra, M., Guo, T., Bobb, S. C., and Kroll, J. F. (2012). When bilinguals choose a single word to speak: Electrophysiological evidence for inhibition of the native language. J. Mem. Lang. 67:1. doi: 10.1016/j.jml.2012.05.001

Moher, D., Liberati, A., Tetzlaff, J., and Altman, D. G. (2009). Preferred Reporting Items for Systematic Reviews and Meta-Analyses: The PRISMA Statement. PLoS Med. 6:e1000097. doi: 10.1371/journal.pmed.1000097

Monaghan, P., Chang, Y. N., Welbourne, S., and Brysbaert, M. (2017). Exploring the relations between word frequency, language exposure, and bilingualism in a computational model of reading. J. Mem. Lang. 93, 1-21. doi: 10.1016/j.jml. 2016.08.003

Ooi, S. H., Goh, W. D., Sorace, A., and Bak, T. H. (2018). From Bilingualism to Bilingualisms: Bilingual experience in Edinburgh and Singapore affects attentional control differently. Bilingual. Lang. Cognit. 21, 867-879. doi: 10. $1017 /$ S1366728918000020

Opitz, C. (2010). L1 attrition and L2 acquisition: Global language proficiency and language dominance in adult bilinguals. EUROSLA Yearb. 10, 248-281. doi: 10.1075/eurosla.10.13opi

Ouzzani, M., Hammady, H., Fedorowicz, Z., and Elmagarmid, A. (2015). Rayyan a web and mobile app for systematic reviews. Systemat. Rev. 5:210. doi: 10.1186/ s13643-016-0384-4

Paolieri, D., Cubelli, R., Macizo, P., Bajo, T., Lotto, L., and Job, R. (2010). Grammatical gender processing in Italian and Spanish bilinguals. Quart. J. Exp. Psychol. 63, 1631-1645. doi: 10.1080/17470210903511210

Pavlenko, A. (2000). L2 influence on L1 in late bilingualism. Iss. Appl. Linguist. 11, $175-205$.

Pavlenko, A. (2004). "Second language influence and first language attrition in adult bilingualism," in First language attrition: Interdisciplinary perspectives on methodological issues, eds M. Schmid, B. Köpke, M. Kejser, and L. Weilemar (Amsterdam: John Benjamins), 47-59. doi: 10.1075/sibil.28.04pav

Pavlenko, A., and Malt, B. C. (2011). Kitchen Russian: Cross-linguistic differences and first-language object naming by Russian-English bilinguals. Bilingual. Cognit. 14, 19-45. doi: 10.1017/s136672891000026x

Perfetti, C., and Stafura, J. (2014). Word knowledge in a theory of reading comprehension. Sci. Stud. Reading 18, 22-37. doi: 10.1080/10888438.2013. 827687

Peristeri, E., Tsimpli, I., Sorace, A., and Tsapkini, K. (2018). Language interference and inhibition in early and late successive bilingualism. Bilingual. Lang. Cognit. 21, 1009-1034. doi: 10.1017/S1366728917000372

Pickering, M. J., and Garrod, S. (2013). An integrated theory of language production and comprehension. Behav. Brain Sci. 36, 329-347. doi: 10.1017/ S0140525X12001495

Ribbert, A., and Kuiken, F. (2010). L2-induced changes in the L1 of Germans living in the Netherlands. Bilingual. Lang. Cognit. 13, 41-48. doi: 10.1017/ S1366728909990320

Ribes, Y., and Llanes, À (2015). First Language Attrition: The Effects of Acculturation to the Host Culture. Proc. Soc. Behav. Sci. 173, 181-185. doi: 10.1016/j.sbspro.2015.02.050

Roberts, L. (2012). Psycholinguistic techniques and resources in second language acquisition research. Sec. Lang. Res. 28, 113-127. doi: 10.1177/ 0267658311418416 
Román, P., Gonzáles, J., Ventura-Campos, N., Rodríguez-Pujadas, A., Sanjuán, A., and Ávila, C. (2015). Neural differences between monolinguals and early bilinguals in their native language during comprehension. Brain Lang. 150, 80-89. doi: 10.1016/j.bandl.2015.07.011

Román, P., Kaan, E., and Dussias, P. E. (2021). Access to verb bias and plausibility information in bilinguals. Bilingual. Lang. Cognit. 2021, 1-13. doi: 10.1017/ S1366728921000924

Runnqvist, E., Gollan, T. H., Costa, A., and Ferreira, V. S. (2013). A disadvantage in bilingual sentence production modulated by syntactic frequency and similarity across languages. Cognition 129, 256-263. doi: 10.1016/j.cognition.2013. 07.008

Sanoudaki, E., and Thierry, G. (2015). Language non-selective syntactic activation in early bilinguals: the role of verbal fluency. Int. J. Bilingual Educat. Bilingual. 18, 548-560. doi: 10.1080/13670050.2015.1027143

Schmid, M. (2010). Languages at play: The relevance of L1 attrition to the study of bilingualism. Bilingual. Lang. Cognit. 13, 1-7. doi: 10.1017/S1366728909990368

Schmid, M. S. (2014). The debate on maturational constraints in bilingual development: A perspective from first-language attrition. Lang. Acquisit. 21, 386-410. doi: 10.1080/10489223.2014.892947

Schmid, M. S., and Dusseldorp, E. (2010). Quantitative analyses in a multivariate study of language attrition: the impact of extralinguistic factors. Sec. Lang. Res. 26, 125-160. doi: 10.1177/0267658309337641

Schmid, M. S., and Fägersten, K. B. (2010). Disfluency Markers in L1 Attrition. Lang. Learn. 60, 753-791. doi: 10.1111/j.1467-9922.2010.00575.x

Schmid, M. S., and Karayayla, T. (2020). The Roles of Age, Attitude, and Use in First Language Development and Attrition of Turkish-English Bilinguals. Lang. Learn. 70, 54-84. doi: 10.1111/lang.12361

Schmid, M. S., and Köpke, B. (2017). The relevance of first language attrition to theories of bilingual development. Linguist. Approac. Bilingual. 7, 637-667. doi: 10.1075/lab.17058.sch

Schmid, M. S., Köpke, B., and de Bot, K. (2013). Language attrition as a complex, non-linear development. Int. J. Bilingual. 17, 675-682. doi: 10.1177/ 1367006912454619

Schmitz, K., Di Venanzio, L., and Scherger, A. L. (2016). Null and overt subjects in Italian and Spanish heritage speakers in Germany. Lingua 180, 101-123. doi: 10.1016/j.lingua.2016.04.004

Sorace, A. (2000). "Differential effects of attrition in the L1 syntax of near-native L2 speakers," in BUCLD 24: Proceedings of the 24th annual Boston University Conference on Language Development, eds S. C. Howell, S. A. Fish, and T. K. Lucas (Somerville, MA: Cascadilla Press), 719-725.

Sorace, A. (2011). Pinning down the concept of "interface" in bilingualism. Linguist. Approac. Bilingual. 1, 1-33. doi: 10.1075/lab.1.1.01sor

Sorace, A. (2020). L1 attrition in a wider perspective. Sec. Lang. Res. 36, 203-206. doi: $10.1177 / 0267658319895571$

Stasenko, A., and Gollan, T. H. (2019). Tip of the tongue after any language: Reintroducing the notion of blocked retrieval. Cognition 193:104027. doi: 10. 1016/j.cognition.2019.104027
StataCorp (2015). Stata Statistical Software: Release 14.2 (14.2). College Station, TX: StataCorp LP.

Steinhauer, K., and Kasparian, K. (2020). Brain Plasticity in Adulthood-ERP Evidence for L1-attrition in Lexicon and Morphosyntax After Predominant L2 Use. Lang. Learn. 70, 171-193. doi: 10.1111/lang.12391

Stuck, A. E., Rubenstein, L. Z., Wieland, D., Vandenbroucke, J. P., Irwig, L., Macaskill, P., et al. (1998). Bias in meta-analysis detected by a simple, graphical. BMJ 316, 629-634. doi: 10.1136/bmj.316.7129.469

Tanner-Smith, E. E., and Tipton, E. (2014). Robust variance estimation with dependent effect sizes: Practical considerations including a software tutorial in Stata and SPSS. Res. Synth. Methods 5, 13-30. doi: 10.1002/jrsm.1091

Tanner-Smith, E. E., Tipton, E., and Polanin, J. R. (2016). Handling Complex Meta-analytic Data Structures Using Robust Variance Estimates: a Tutorial in R. J. Dev. Life Course Criminol. 2, 85-112. doi: 10.1007/s40865-016-0026-5

Titone, D., Libben, M., Mercier, J., Whitford, V., and Pivneva, I. (2011). Bilingual lexical access during $\mathrm{L} 1$ sentence reading: The effects of $\mathrm{L} 2$ knowledge, semantic constraint, and L1-L2 intermixing. J. Exp. Psychol. 37, 1412-1431. doi: 10.1037/ a0024492

Tsimpli, I., Sorace, A., Heycock, C., and Filiaci, F. (2004). First language attrition and syntactic subjects: A study of Greek and Italian near-native speakers of English. Int. J. Bilingual. 8, 257-277. doi: 10.1177/1367006904008003 0601

Walenski, M., Europa, E., Caplan, D., and Thompson, C. K. (2019). Neural networks for sentence comprehension and production: An ALE-based metaanalysis of neuroimaging studies. Hum. Brain Mapp. 40, 2275-2304. doi: 10. $1002 / \mathrm{hbm} .24523$

Wartenburger, I., Heekeren, H. R., Abutalebi, J., Cappa, S. F., Villringer, A., and Perani, D. (2003). Early setting of grammatical processing in the bilingual brain. Neuron 37, 159-170. doi: 10.1016/s0896-6273(02)01150-9

Conflict of Interest: The authors declare that the research was conducted in the absence of any commercial or financial relationships that could be construed as a potential conflict of interest.

Publisher's Note: All claims expressed in this article are solely those of the authors and do not necessarily represent those of their affiliated organizations, or those of the publisher, the editors and the reviewers. Any product that may be evaluated in this article, or claim that may be made by its manufacturer, is not guaranteed or endorsed by the publisher.

Copyright (c) 2022 Román and Gómez-Gómez. This is an open-access article distributed under the terms of the Creative Commons Attribution License (CC BY). The use, distribution or reproduction in other forums is permitted, provided the original author(s) and the copyright owner(s) are credited and that the original publication in this journal is cited, in accordance with accepted academic practice. No use, distribution or reproduction is permitted which does not comply with these terms. 